\title{
Nahçıvan Bölgesinin Tunç Çağı Yerleşimlerinde Bulunan Çömlekçi Fırınları ve Atölyeleri
}

\section{Pottery Kilns and Workshops in the Bronze Age Settlements of the Nakhchivan Region}

\author{
Toğrul Halilov*
}

\section{Öz}

Çömlekçilik, Nahçıvan'ın en eski sanat dallarından biri olarak kabul edilmektedir. Nahçıvan bölgesinin Tunç Çağı yerleşim yerlerinde bu sanat dalıyla bağlantılı çok sayıda arkeolojik veri bulunmaktadır. Bu tür arkeolojik veriler içerisinde yer alan çömlek atölyelerinin ve fırın kalıntılarının bilimsel önemi vardır. Bu arkeolojik veriler hakkında ayrı ayrı kaynaklarda ve arkeolojik kazı raporlarında bilgiler verilmiş olsa da kapsamlı bir biçimde incelenmemiştir. Bu nedenle Nahçıvan'da bulunan çömlek atölyeleri ve fırınlar ile ilgili detaylı bir çalışma yapılmasına ihtiyaç duyulmuştur.

Çalışma sonucunda çömlekçiliğin Tunç Çağı'nda geliştiği, Kültepe I ve Kültepe II yerleşim yerlerinin Nahçıvan'ın önemli çömlekçilik merkezlerinden olduğu tespit edilmiştir. Atölyede ve fırınların çevresinde, yanarak kömürleşmiş hayvan kemikleri yanında üzerinde ve kenarında yağ izi olan kil kapların bulunması, bu fırınlarda odunun yanı sıra hayvan kemiklerinin de kullanıldığını göstermektedir. Fırının çevresindeki taş ve kemik aletler ise kapların ve diğer seramik objelerin yapımında ve süslemesinde kullanılmıştır. Çömlekçiler basit kapların yanı sıra boyalı kaplar da yapmışlardır. Orta Tunç Çağı́ndan itibaren boya ile süslenmiş kapların yaygın olması, Nahçıvan`ın “Boyalı Kaplar Kültürü”nün önemli merkezlerinden biri olduğunu kanıtlamaktadır.

Bu çalışmada Nahçıvan Özerk Cumhuriyeti içerisinde bulunan Kültepe I ve Kültepe II yerleşim yerlerinde yapılan arkeolojik kazılarda ortaya çıkarılan çömlekçi fırınları hakkında bilgi verilmiş ve Tunç Çağı́nda bölgede çömlekçiliğin gelişimine dair değerlendirmeler yapılmıştır.

\section{Anahtar Kelimeler}

Nahçıvan, Tunç Çağı, çömlekçilik, atölye, fırın, Kültepe

\section{Abstract}

Pottery is one of the ancient handicrafts of Nakhchivan. Many archaeological materials were obtained from the Bronze Age monuments of Nakhchivan regarding this handicraft. Among them, pottery workshops and pottery spheres have a peculiar place. Although these archaeological data have been mentioned separately in some research papers and reports, they have not been studied extensively. For this reason, it was necessary to conduct a detailed study of pottery workshops and furnaces located in Nakhchivan.

As a result of the study, it was determined that pottery developed in the Bronze Age, and the settlements of Kultepe I and Kultepe II were some of the important pottery centers of Nakhchivan. The presence of clay containers with traces of oil on the top and edge in the workshop and around the furnaces, as well as burnt charred animal bones, indicates that

* Sorumlu Yazar: Toğrul Halilov (Doç. Dr.), Azerbaycan Bilimler Akademisi, Nahçıvan Bölümü, Nahçıvan, Azerbaycan. E-posta: x.toqrul@gmail.com ORCID: 0000-0002-3703-8315

Atıf: Halilov, Togrul. "Nahçıvan Bölgesinin Tunç Çağı Yerleşimlerinde Bulunan Çömlekçi Fırınları ve Atölyeleri." Art-Sanat, 17(2022): 177-191. https://doi.org/10.26650/artsanat.2022.17.880656 
animal bones, as well as wood, were used in these furnaces. Stone and bone tools around the kiln were used to make and decorate pots and other ceramic products. Potters made painted vessels as well as simple vessels. The widespread use of containers decorated with paint since the Middle Bronze Age proves that Nakhchivan is one of the important centers of the "Culture of Painted Containers".

In this study, information was given about the pottery kilns unearthed in the archaeological excavations in Kultepe I and Kultepe II settlements in the Nakhchivan Autonomous Republic, and evaluations were made about the development of pottery in the region during the Bronze Age.

Keywords

Nakhchivan, Bronze Age, pottery, kiln, workshop, Kultepe

\section{Extended Summary}

The Nakhchivan Autonomous Republic has an ancient and rich history. There are many archaeological monuments in the territory of the autonomous republic. A lot of archaeological material has been found in these monuments. Each of them has a special place in the study of our history, material, and spiritual culture. A group of such archaeological materials consists of pottery kiln and workshops found in the Bronze Age monuments of Nakhchivan. We decided to research these because they have not been studied thoroughly before. During the research, pottery kilns and workshops found in the Bronze Age monuments of the Nakhchivan region were catalogued using reports and library materials, their period, scientific significance for Azerbaijani archaeology and other issues were determined. During the research, it was determined that a pottery kiln was found in the Bronze Age archaeological monuments in the Nakhchivan region from the monuments of Kultepe I, Kultepe II, Chalkhangala, Shortepa. Pottery kilns belonging to the Early Bronze Age were dated back to the Kultepe I settlements, and pottery kilns belonging to the Early and Middle Bronze Age were dated back to the Kultepe II settlement.

Kultepe I settlement is $10 \mathrm{~km}$ far from the city center of Nakhchivan. It is located within the borders of Kultepe village of Babek district in the northeast. In 1951 under the leadership O. H. Habibullayev, the archaeological expedition of the History Institute of Azerbaijan A.S. began to research Kultepe I. During 1951-1964 investigations four cultural layers about different ages were discovered. The total thickness of the cultural layers is $22,2 \mathrm{~m}$. The Early Bronze Age layer overlying the Chalcolithic Age layer is 8.5-9 m thick. The Middle and Late Bronze Age layer overlying the Early Bronze Age layer is $2 \mathrm{~m}$ thick. The Early Iron Age layer overlying the Middle and Late Bronze Age layer is 1.5-2 m thick. Different material and cultural examples from of Kura-Aras culture were discovered from this layer. They mainly were built round but sometimes square. They were constructed on a stone basement of mortar or air bricks. During O. H. Habibullayev's investigations, it was determined that the roundshaped buildings were covered with coniclike, but square-shaped buildings with flat cover. The third stage of Kultepe I belongs to the Middle and Late Bronze Age. Very few construction remnants about this period were discovered. For O. H. Habibullayev 
they are mainly square and stones, air bricks were used as construction materials. During archaeological investigations, different tools prepared from stone, bone and bronze were discovered from this layer. The clay product discovered from this layer was pink. They were sometimes in grey and black colour and burnt perfectly. Most of the painted dishes are pink.

Kultepe II settlement is $10 \mathrm{~km}$ away from the northeast of Nakhchivan while it is $5 \mathrm{~km}$ away from the north of the Kultepe I settlement. The western part of the settlement, which spreads over a very large area (3 hectares), has been largely destroyed because of the changed bed of the Cehri Stream. Early, Middle and Late Bronze Age cultural layers in the area were unearthed in the archaeological excavations conducted by Osman Habibullayev and Veli Aliyev between 1968-1988. The Early Bronze Age layer is $5.5 \mathrm{~m}$, the Middle Bronze Age layer is $4.5 \mathrm{~m}$ thick. There are six excavation sites in Kultepe II but only in second excavation site, the investigation had been continued till the virgin land bed. As a result of investigations, three cultural layers were discovered. The first layer is about the early Bronze Age, and it is characteristic of the material-cultural examples belonging to Kura-Aras culture. During investigations 14 construction layers were discovered in the area. The lower construction layers were round formed, but the upper layers were round-shaped and square buildings are characteristic of the Bronze Age of Kultepe II. A hole of a stone for a central column holding a conically shaped cover inside one round formed building was discovered. Firstly, mortar and then air bricks were used in the construction of these buildings. Second layer of Kultepe II settlement belongs to the Middle Bronze Age. As a result of investigations, four construction layers were discovered. The discoveries from this layer are characteristic of the old city culture. Investigations show that the settlement around of which was enforced had appeared in Kultepe II at the end of III millennium B.C. Along with a pottery kiln, a potter's workshop of the Middle Bronze Age was also registered at the Kultepe II settlement. Two pottery kilns of the Early Bronze Age were recorded at the Kultepe I settlement. Pottery kilns were found on the third and fifth floors of the building. Remains of pottery kilns were also dated back to the seventh and eleventh construction floors of the Early Bronze Age Kultepe II settlement. Remains of pottery kilns and workshops were found on the second and fourth floors of the Kultepe II settlement of the Middle Bronze Age. The kiln belongs to the group of the "White Sea" type kiln considering their shape and characteristics. The kiln registered in the monuments of Kultepe I and Kultepe II, the workshop complex found in Kultepe II, the jars filled with paint, all painted pottery, many simple and painted pottery prove that these settlements were one of the main pottery centers of Nakhchivan in the Bronze Age. The accumulation of large quantities of painted pottery and a thick layer of coal around the kiln and the workshop was due to the mass production there. The discovery of charred animal bones in the workshop and around the kiln, 
as well as clay pots with traces of fat on and around them, also proved that animal bones and other fuels were burned in the kiln along with firewood. The stone and bone tools around the kiln were used to make pottery and other ceramic products. 


\section{Giriş}

Nahçıvan Özerk Cumhuriyeti içerisinde çok sayıda arkeolojik yerleşim ve buna bağlı olarak da önemli arkeolojik veriler tespit edilmiştir. Söz konusu verilerin büyük bölümünü çömlekçi firınları ve atölyeleri oluşturmaktadır. Nahçıvan bölgesindeki Tunç Çağı yerleşim yerlerinde bulunan çömlekçi fırınlarının ve atölyelerinin araştırılması Azerbaycan'daki arkeoloji çalışmalarının önemli bir bölümünü oluşturmaktadır. Aynı zamanda bu konuda elde edilen veriler oldukça sınırlıdır. Bu alanda şimdiye kadar kapsamlı bir çalışma yapılmamış olması belirtilen konunun yeniden incelenmesi ihtiyacını doğurmuştur. Çalışma, alan araştırması, literatür taraması ve arkeolojik kazı raporlarının incelenmesi şeklinde yürütülmüştür. Araştırma esnasında Nahçıvan bölgesindeki Tunç Çağı'na ait yerleşim yerlerinde bulunan çömlekçi firınları ve atölyeleri sistematik olarak incelenmiştir. Ayrıca araştırmada karşılaştırma yönteminin yanı sıra, farklı bilimsel araştırma metotları ve çeşitli kaynaklar da kullanılmıştır.

\section{Çömlekçi Furınları ve Atölyeleri}

Nahçıvan bölgesinin Tunç Çağı yerleşim yerlerinde bulunan çömlekçi firınları genel olarak Erken ve Orta Tunç çağına aittir. Erken Tunç Çağı'na ait çömlekçi firınlarının kalıntıları Kültepe I yerleşim yerinin III., V. ${ }^{1}$, Kültepe II yerleşiminin VII., XI. yapı katında ${ }^{2}$ bulunmaktadır.

Kültepe I yerleşimi Nahçıvan şehir merkezinin 10 km kuzeydoğusunda ve Nahçıvan Çayı'nın doğusunda yer alan Babek ilçesine bağlı Kültepe köyünün sınırları içinde bulunmaktadır. Yerleşim yerinde 1951-1964 yılları arasında Osman Habibullayev başkanlığında sürdürülen arkeolojik kazılar sırasında Kalkolitik Çăğ’ndan Erken Demir Çağı'na kadarki zaman dilimine ait $22 \mathrm{~m}$ kalınlığında kültür katmanları ortaya çıkartılmıştır. Kalkolitik Çağı tabakasının üzerinde yer alan Erken Tunç Çağı tabakası 8,5-9 m; Erken Tunç Çağı tabakası üzerinde yer alan Orta ve Son Tunç Çağ tabakası $2 \mathrm{~m}$; Orta ve Son Tunç Çağ tabakasının üzerinde yer alan Erken Demir Çağı tabakası ise 1,5-2 m kalınlığındadır. Bu tabaka küçük bir alanı kapsamaktadır. Kazı esnasında yerleşimdeki mimari kalıntıların büyük bir kısmının yoğun biçimde tahrip olduğu görülmüştür. Buna rağmen kazıda çeşitli arkeolojik veriler ortaya çıkartılmıştır. ${ }^{3}$

Kültepe I yerleşiminin III. yapı katında bulunan çömlekçi firını 28 numaralı yapının güneydoğu kesiminde, giriş kapısının sağ tarafında, duvara birleşik şekilde tespit edilmiştir. Çap 15,5 metredir. Ham tuğladan $42 \times 18 \times 12 \mathrm{~cm}$ boyutunda yapılmış ve kil ile sıvanmıştır. Fırının ateş odası kubbe şeklinde ve hafif düzensiz dikdörtgen plan üzerine yapılmıştır. Nispeten sağlam olan kısmı $0,78 \mathrm{~m}$ genişliğinde ve $0,18 \mathrm{~m}$

1 Osman Abibullayev, Enolit i Bronza na Territorii Nahiçevanskoy ASSR (Bakü: İlim Yayınları, 1982), 87, 89; Abbas Seidov, Rannebronzovaya Kultura Nakçvana (Voronej: İlim Yayınları, 2002), 22, 25.

2 Abbas Seidov, Pamyatniki Kura-Arakskoy Kulturı Nakçıvane (Bakü: Bilig Yayınları, 1993), $24-25$.

3 Osman Abibullayev, Enolit i Bronza na Territorii Nahiçevanskoy ASSR, 24-179 
yüksekliğindedir (G. 1/1). V. kattaki firın, 21 numaralı binanın kuzey kesiminde yer almaktadır. Duvarları $40 \mathrm{~cm}$ kalınlığında, $20 \mathrm{~cm}$ yüksekliğindedir ve sağlam olarak durmaktadır. Göreceli olarak sağlam olan kısmı $0,18 \mathrm{~m}$ yüksekliğinde ve $0,65 \mathrm{~m}$ genişliğindedir (G.1/2). Her iki fırının etrafında kül ve seramik parçaları bulunmuştur4.

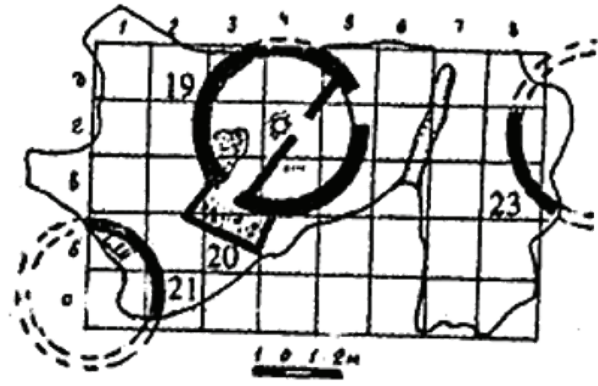

1

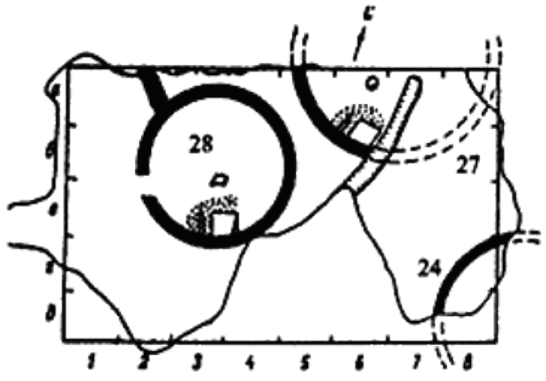

2

G. 1: Kültepe I yerleşim yerinin Erken Tunç Çağına ait III. (G. 1/1) ve V. (G. 1/2) yapı katının planı (Osman Abibullayev, Enolit i Bronza na Territorii Nahiçevanskoy ASSR, 274, ris. 13 b: 275, ris. 13 a).

Kültepe II yerleşimi Nahçıvan kentinin 10 km kuzeydoğusunda, Kültepe I yerleşiminin 5 km kuzeyinde bulunmaktadır. Çok geniş bir alana (3 hektar) yayılan yerleşim yerinin batı kısmı Cehri Çayı'nın değiştirilen yeni yatağı yüzünden büyük ölçüde tahrip olmuştur. Yerleşim yerinde 1968-1988 yılları arasında Osman Habibullayev ve Veli Aliyev başkanlığında sürdürülen arkeolojik kazılarda Erken, Orta ve Son Tunç Çağı kültür tabakaları ortaya çıkarılmıştır. Erken Tunç Çağı tabakası 5,5 m, Orta Tunç Çağ tabakası 4,5 m kalınlığındadır. Yapılan kazı çalışmalarında MÖ 2. bin yılın başlarına ait etrafı duvarla çevrili olan bir iç kale ortaya çıkarılmıştır. Kale duvarları, Nahçıvan Çayı'nın yatağından elde edilen iri çakı1 taşlarının çamurla örtülmesiyle yapılmıştır. Ortaya çıkarılan duvarların uzunluğu 35 m, genişliği 2-2,5 m arasında değişmektedir. ${ }^{5}$ İç kale, Orta Tunç Çağı'nda Kültepe'nin önemli bir yönetim merkezi olduğunu göstermektedir.

Kültepe II yerleşiminin VII. ve XI. yapı katlarında bulunan Erken Tunç Çăğ’na ait çömlekçi firınları, dikdörtgen biçimde ateşe dayanıklı kilden yapılmıştır. Yerleşim yerinin VII. yapı katındaki firın 16 numaralı yapının batı kısmında bulunmaktadır, pişmiş tuğladan yapılmış ve kille sıvanmıştır. Fırının pişirme odasının çap1 2x2,5 metredir. Ateş odası, pişirme odasının doğu tarafında, $40 \mathrm{~cm}$ aşağıda yer almaktadır (G. 2/1). XI. yapı katındakı firın, 5 numaralı yapının kuzeydoğu kesiminde tespit edilmiştir (G. 2/2). Göreceli olarak sağlam olan kısmı 0,52 m genişliğinde, 0,3 m yüksekliğindedir. Pişirme odası 1,5x2,5 m boyutundadır. VII. kattaki fırın gibi yanma odası doğu tarafta bulunan pişirme odasının $40 \mathrm{~cm}$ aşağısında yer almaktadır ${ }^{6}$.

4 Osman Abibullayev, Enolit i Bronza na Territorii Nahiçevanskoy ASSR, 87, 89.

5 Veli Aliyev, Kultura Epoxi Sredney Bronzı Azerbaydjana (Bakü: İlim Yayınları, 1991), 25-26.

6 Abbas Seidov, Pamyatniki Kura-Arakskoy Kulturı Nakçıvane (Bakü: Bilig Yayınları, 1993), 24-25. 


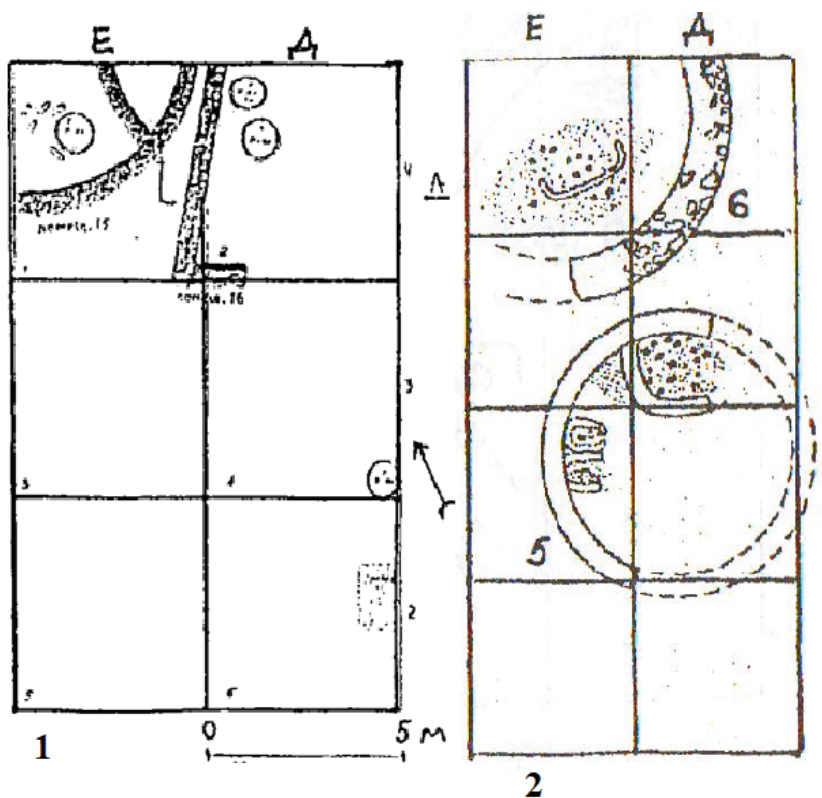

G. 2: Kültepe II. yerleşiminin Erken Tunç Çağı'na ait VII. (G. 2/1) ve XI. (G. 2/1) yapı katının planı (Abbas Seidov, Rannebronzovaya Kultura Nakçvana, 183, ris. 6, XI; 185, ris. 8, 7).

Orta Tunç Çağı'na ait çömlekçi firınları Şortepe ${ }^{7}$, Kültepe II $^{8}$, Çalkankale ${ }^{9}$ yerleşim yerlerinde tespit edilmiştir. Şortepe, Çalkankale yerleşim yerlerindeki çömlekçi firınları tamamen tahrip olduğundan onlar hakkında arkeolojik kaynaklarda, kazı raporlarında yeterli bilgiler bulunmamaktadır. Kültepe II yerleşiminde çömlekçi fırınlarının yanı sıra atölyeye ait kalıntılar da ortaya çıkarılmıştır. Kültepe II yerleşiminde 1968-1975 yıllarında yapılan arkeolojik kazılarda, birinci kazı alanının IV. tabakasında 0,5-1,5 m derinlikte Orta Tunç Çă̆ı'na ait çömlekçi firınlarının ve atölyelerinin kalıntıları tespit edilmiştir (G. 3). Yerleşim yerindeki çömlekçi firınlarından biri diğerlerine kıyasla daha sağlam şekilde günümüze ulaşmıştır. Bu firın 3x3 metre alanda tuğladan, dairesel planda inşa edilmiştir. Fırının içerisinde kül kalıntıları birikmiş, duvarları ateşin etkisinden kararmıştır. Fırının göreceli olarak sağlam olan kısmı 16-18 cm yüksekliğinde, 0,52 m genişliğindedir. Bununla birlikte çömlekçi atölyesi $15 \mathrm{~m}^{2}$ alanı kapsamaktadır. Atölyede kül, boyalı ve boyasız kapların parçaları bulunmuştur. Boyalı kapların çoğu tek renklidir. Bu kazı alanının IV. yapı katında yer alan çömlekçi atölyelerinin duvarları taşla örülmüş, firının çevresinde de taşla yapılmış duvar bulunmaktadır. $9 \mathrm{~m}^{2}$ alanda kül ve kömür kalıntıları tespit edilmiştir. Fırının kapların konulduğu bölümü tamamen dağılmıştır. Yanma odası işlevi gören bölümün 1,2 metrelik bir kısmı sağlam kalabilmiştir ${ }^{10}$.

7 Alesker Alekperov, İssledovanie po Arxkeoloqi Azerbaydjana (Bakü: Az. SSR Yayınları, 1960), 55.

8 Veli Aliyev, Azerbaycan'da Tunç Devrinin Boyalı Kablar Medeniyyet (Bakü: İlm Yayınları, 1977), 27.

9 Veli Aliyev, Kultura Epoxi Sredney Bronzi Azerbaydjana, 31.

10 Veli Aliyev, Azerbaycan'da Tunç Devrinin Boyalı Kablar Medeniyyet, 32. 


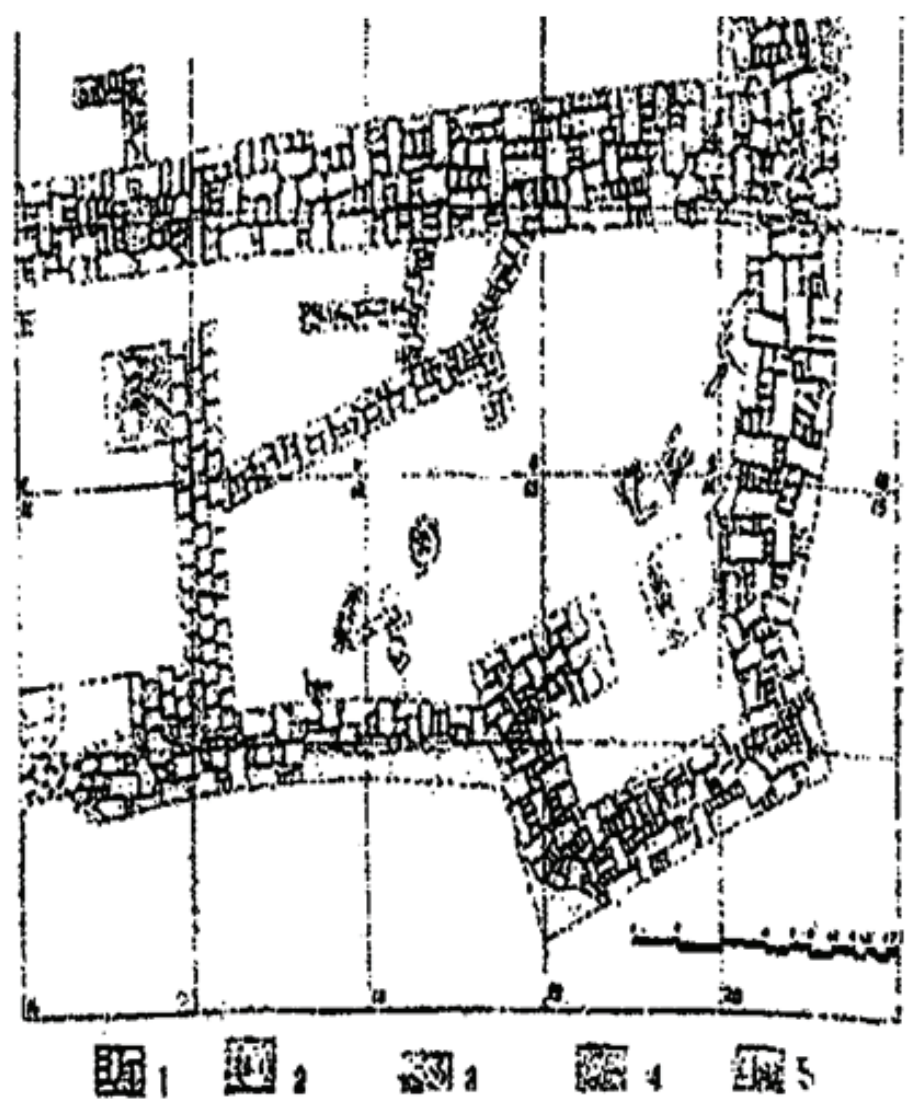

G. 3: Kültepe II yerleşiminde bulunan Orta Tunç Çă̆ı'na ait çömlekçi atölyelerinin planı (Veli Aliyev, Kadim Nahçıvan, 10).

Yerleşim yerinin II. kazı alanında, kale duvarının kuzeydoğu kısmıyla birleşik bölümünde MÖ 17. yüzyıla ait olduğu düşünülen çömlekçi atölyesi ve çömlekçi firını bulunmaktadır. Buradaki atölye dikdörtgen plana sahiptir (G. 4) ve alanı $120 \mathrm{~m}^{2}$ dir. Güney kesimindeki sağlam kalan duvarın uzunluğu 24 m, genişliği 6,2 m, diğer kesimlerde 4,5 metredir. Fırından yayılan 1sının etkisiyle güney duvarı doğu duvarından daha fazla yanmıştır. Batı duvarı, dikdörtgen biçimindedir. Batı duvarının genişliği 80 $\mathrm{cm}$, yüksekliği $50 \mathrm{~cm}$, uzunluğu 6 metredir. Güney duvarının uzunluğu $6,2 \mathrm{~m}$, yüksekliği $50 \mathrm{~cm}$, genişliği 1 metredir. Güney kesimindeki alan 36 metrekaredir. Doğu duvarı, kale duvarının bir parçasıyla değiştirilmiştir. Kullanılmadığı için içeriden o duvara paralel başka bir duvar örülerek orada bir çömlekçi atölyesi kurulmuştur ${ }^{11}$. 


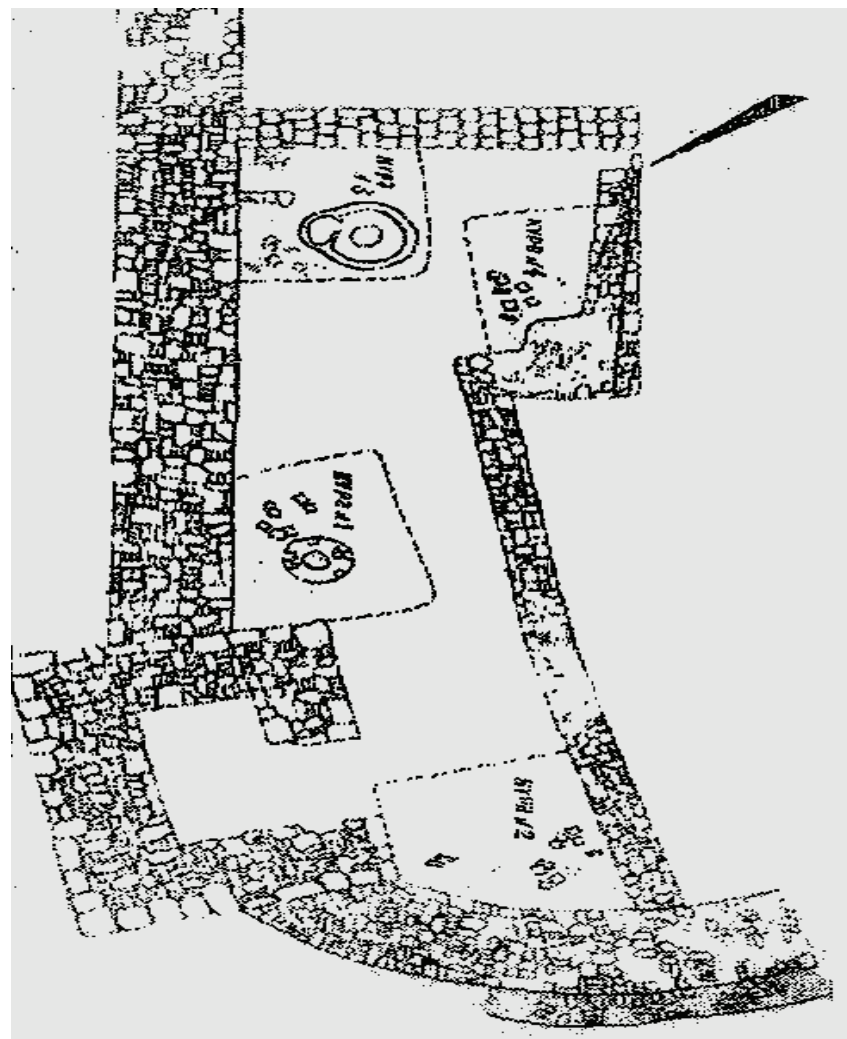

G. 4: Kültepe II yerleşiminde bulunan Orta Tunç Çağı'na ait çömlekçi atölyesinin planı (Veli Aliyev, Kadim Nahçıvan, 45).

Atölyenin içinde dört yerde çömlek firınının kalıntıları tespit edilmiştir. Bir numaralı firın, yerleşim yerinin kuzey bacasının kuzeydoğu kısmında, kale duvarının iç tarafında bulunmaktadır. Alanı $12 \mathrm{~m}^{2}$ dir. Ağır hasar görmesine rağmen diğerlerine oranla daha sağlam kalabilmiştir. Fırının sağlam kalmış kalıntıları incelendiğinde ham tuğlalarla, dikdörtgen planda inşa edildiği tespit edilmiştir. Fırın; pişirme odasından, yanma odasından, hava bacasından ve havanın fırına dâhil olmasını sağlayan delikten oluşmaktadır. Pişirme odası kare şeklinde ham tuğladan dikdörtgen planda yapılmıştır. Yanma odası (ateş bölümü) fırının doğu kısmında kale duvarının yakınında yer almaktadır. Fırının havalandırma odas $40 \mathrm{~cm}$ yüksekliğinde, $60 \mathrm{~cm}$ genişliğinde silindirik biçimdedir. Üzerine havalanma için $20 \mathrm{~cm}$ genişliğinde delik yapılmıştır. Yerleşim alanında $20 \mathrm{~cm}$ kalınlığındaki yanmış tuğla kalıntılarının içerisinde firına ait malzemeler bulunmuştur ${ }^{12}$ (G. 4/1). Tuğlanın altında çanak-çömlek, kömür kalıntıları, firının içerisinden on beş adet gri ve monokrom renkli kil kaplar; atölyenin kale duvarına yakın kısmında ise çeşitli iş aletleri ve hayvan kemikleri tespit edilmiştir. 
İki numaralı firın, bir numaralı firının kuzeyinde yer almaktadır. Bulunduğu alandan yeteri kadar kömür toplanmıştır. Bu firının yanma odası, savunma duvarına bitişik tuğlayla yarım dairesel biçimde yapılmıştır. Sağlam olan kısmı $40 \mathrm{~cm}$ yüksekliğinde, $60 \mathrm{~cm}$ genişliğindedir ancak bir numaralı firın gibi o da ağır hasar nedeniyle dağılmıştır. Sağlam kalan mimari kalıntılar, aslında onun $12 \mathrm{~m}^{2}$ alanı kapladığını göstermektedir (G. 4/2). Bir numaralı firın gibi iki numaralı fırının da çevresinden ve içinden kül, kömür kalıntıları, gri, siyah renkli basit ve boyalı kil kaplar toplanmıştır'13.

Kale duvarının kuzey bacasının yakınında, $90 \mathrm{~cm}$ uzunluğunda ve $75 \mathrm{~cm}$ genişliğinde dikdörtgen planda yapılmış firının kalıntıları bulunmuştur. Duvarları tamamen dağıldığından dolayı firının yüksekliğini tespit etmek mümkün olmamıştır. Fırının içerisinde kül, üstünde dikdörtgen biçimli bir seramik parçası, yakınında bir insan iskeletinin kalıntıları, koyu gri renkli, üzeri üçgen desenlerle süslenmiş bir çömleğe benzer kil kap yer almaktadır (G. 5/1c). İskeletin üzerinde ve çevresinde çok sayıda kırık tuğla parçaları, yanmış ve yarı yanmış ahşap kalıntıları tespit edilmiştir. Bu kalıntılar çömlekçi atölyelerinin saldırıya uğramış veya yaşanan bir deprem sırasında yapının yıkıldığını ve çalışan işçilerin atölyeden kaçamayarak enkaz altında kalmış olabileceği ihtimalini düşündürmektedir ${ }^{14}$.

Kültepe II yerleşim yerinde üç numaralı çömlek firını atölyenin güneydoğu köşesinde yer almaktadır (G. 4/3). Fırının kapladığı alan $14 \mathrm{~m}^{2}$ dir. Fırın ham tuğlayla dikdörtgen planda yapılmıştır ve sağlam kalan kısmının genişliği 1,7 cm, yüksekliği $10 \mathrm{~cm}$, uzunluğu 2 m'dir. Fırının zemini ve duvarları 1sı nedeniyle siyah renge dönüşmüştür. Fırın yerinden çok sayıda monokrom boyalı kil kapların kırık parçaları toplanmıştır. Yanma (ateş) odası sarı renkli kilden, uzun ve yarım dairesel planda yapılmıştır. Yanma odasının zemininde 30-40 cm kalınlığında kül kalıntısı ve seramik parka kalıntıları tespit edilmiştir. Bu kalıntılardan biri özellikle ilgi çekicidir. Bu seramik parçası kubbe biçimlidir. Üzerinde üst bölümde bir, gövdesinde ise iki delik bulunmaktadır ${ }^{15}$ (G. 4/4). Bu seramik parçasının hangi amaçla yapıldığını belirlemek oldukça zordur. Bunun başlıca nedenlerinden biri bu tip seramik bulgusunun şimdiye kadar Nahçıvan bölgesinin diğer arkeolojik yerleşim yerlerinde bulunmamasıdır. Yapılan incelemeler sonucunda seramik parçasının firının içinde bulunması ve üzerinde deliklerin olması dikkate alındığında parçanın firınla ilgili olduğu tahmin edilmektedir. Fırının çevresinde ve içerisinde çok sayıda arkeolojik veriler bulunmuştur. Bu arkeolojik veriler arasında yer alan iş aletleri taştan ve tunçtan yapılmıştır. Seramik ürün buluntuları, gri ve siyah renkte, basit ve boya ile süslenmiş kil kaplardan oluşmaktadır. Hayvan kemiklerinin ise çoğu yanmıştır. Fırında bulunan tarak biçimli iş aletlerinden bir tanesinin benzerine Üzerliktepe yerleşiminde rastlanmıştır ${ }^{16}$.

13 Veli Aliyev, Kadim Nahçıvan, 32.

14 Veli Aliyev, Kadim Nahçıvan, 33.

15 Veli Aliyev, Kadim Nahçıvan, 34.

16 Veli Aliyev, Kadim Nahçıvan, 31. 


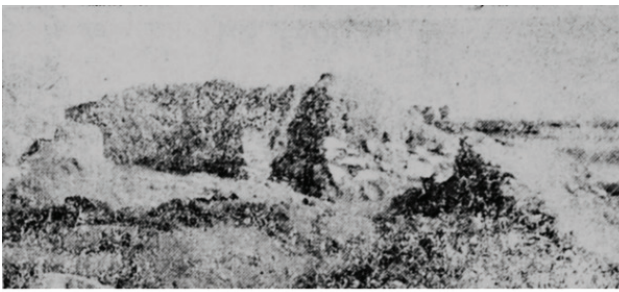

1

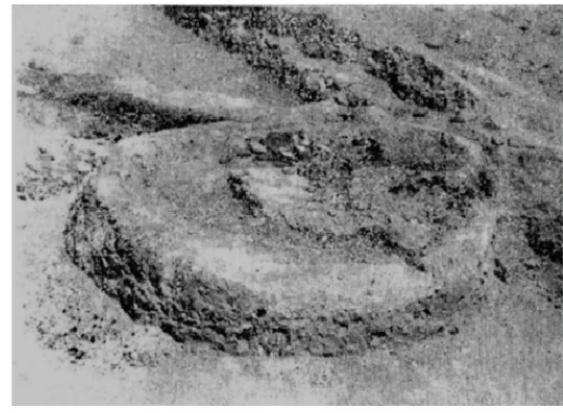

3

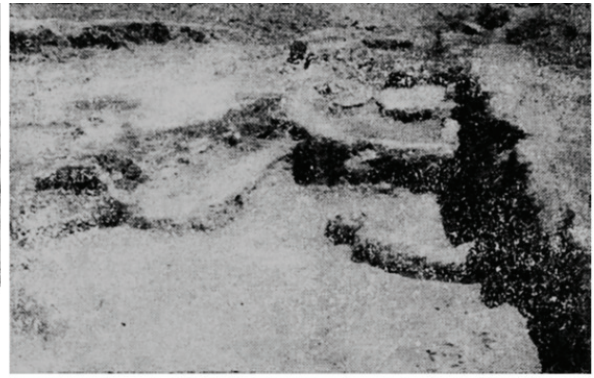

2

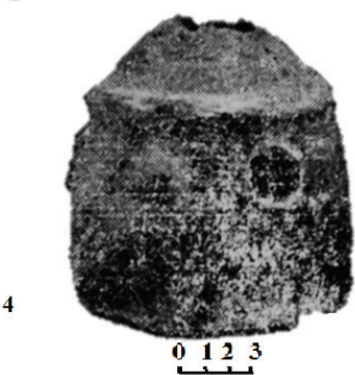

G. 4: Kültepe II yerleşiminde bulunan çömlekçi firınının kalıntıları

(Veli Aliyev, Kadim Nahçıvan, 31, 32, 34)

Dört numaralı fırın atölyenin batı kısmında bulunmaktadır ve alanı 12 metrekaredir. Ham tuğladan dikdörtgen plan üzerine inşa edilmiştir. Yanma odası kil ile kaplıdır. F1rının üst kısmı kubbe biçimindedir. Diğer fırınlar gibi dört numaralı fırının da yanma odasında çok sayıda kil kap parçaları bulunmaktadır. Tamamen dağıldığından dolayı fırının planını belirlemek mümkün olmamıştır.

Kültepe II yerleşiminin II. kazı alanının üst kısmında 70-80 cm kalınlığında bir kültür tabakasında kaydedilen IV. yapı katında $25 \mathrm{~m}^{2}$ alana sahip bir odanın yakınında büyük taşlardan yapılmış diğer bir çömlek atölyesi bulunmuştur. Bu çömlek atölyesinde $9 \mathrm{~m}^{2}$ alanda kül ve kömür kalıntılarının olduğu tespit edilmiştir. Kül ve kömür kalıntılarının altında ise 1,2 m genişliğinde diğer bir çömlekçi fırını bulunmuştur. $\mathrm{Bu}$ ikinci çömlekçi fırının sağlam kalan bölümünün yüksekliği 16-18 cm, duvarının kalınlığı ise $12-15 \mathrm{~cm}$ 'dir.

Kültepe II yerleşiminde önceki yıllarda olduğu gibi 2009-2014 yıllarında arasında yapılan arkeolojik kazılarda da çömlekçi fırınları ve çömlekçi atölyesi kalıntıları bulunmuştur ${ }^{17}$ (G. 5).

17 Veli Aliyev ve Aide Memmedova, “II Kültepe Yaşayış Yerinde 2009 Yıl Tedkikatları,” Azerbaycanda Arkeoloji Tedkikatlar-2009 (Bakü: Xezer Üniversitesi Yayınları, 2010), 126-130; Veli Aliyev ve Aide Memmedova, "II Kültepe Yaşayış Yerinde Yini Tedkikatlar (2010)," Azerbaycanda Arkeoloji Tedkikatlar-2010 (Bakü: Xezer Üniversitesi Yayınları, 2011), 126-135. 

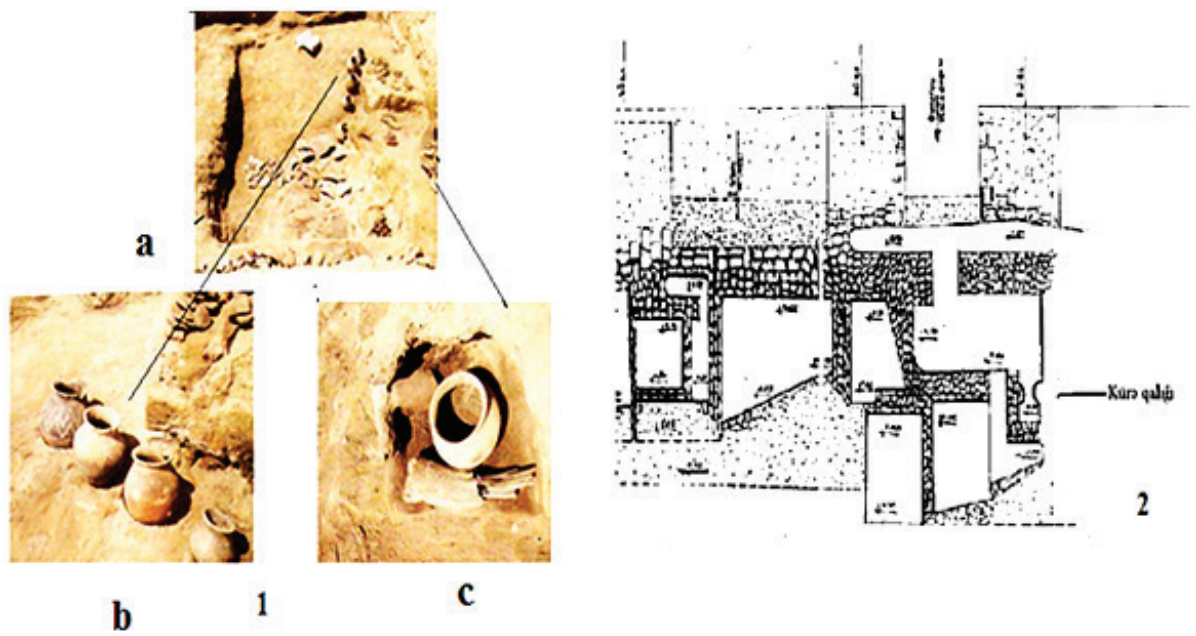

G. 5: Kültepe II yerleşim yerinde 2010 y1lında çömlekçi atölyesinde bulunan kil kaplar (G. 5/1a, b, c) (Veli Aliyev ve Aide Memmedova, Azerbaycanda Arkeoloji Tedkikatlar (2010), 127) ve çömlekçi atölyesin planı (G. 5/2) (Plan Gülnare Kanberova tarafından 2014 yılında çizilmiş ve daha önce herhangi bir kaynakta yayınlanmamıştır).

2009 yılında yapılmış araştırmada Kültepe II yerleşimin kuzeybatı savunma duvarının yakınında, kazı alanının güney kesimindeki V. ve II. alanlarda çömlek atölyesi ve firınları tespit edilmiştir. Atölyenin duvarları taştan ve tuğladan, fırının duvarları 32x20 cm ölçüde tuğladan yapılmıştır ve doğu-batı yönünde kale duvarına bitişiktir. Son Tunç Çağı'nda kuzey duvarında bazı onarım ve inşaat çalışmaları yapılmıştır. Atölye ve fırınların çevresinde kilden çanak-çömlek parçaları, taştan ve hayvan kemiklerinden yapılmış iş aletleri bulunmuştur. Fırında kapların pişirildiği bölüm temizlenirken kül tabakasının altından koyu sarı, sarı, pembe ve beyaz kaya kalıntıları, parlak mineraller, kil kaplar ve yanmış kuş kemikleri ortaya çıkarılmıştır. Fırının duvarları dağılarak kil kapların üzerine düştüğünden dolayı bu parçaların çoğu kırılmış hâldedir. Kapların firında yan yana belirli bir şekilde konulduğu anlaşılmaktadır.

2009 yılında yapılan kazılar esnasında ortaya çıkarılan çömlek atölyelerinin yerinde 2010 yılında yapılan arkeolojik kazılarda da 20-30 cm kalınlığındaki kültürel tabakanın altında atölyenin yeni duvarları bulunmuştur. Orada aynı zamanda 1,8 m derinlikte tuğladan 2,5x2,5 m ölçüde yapılmış binaların kalıntıları da tespit edilmiştir. Atölye'nin tabanları gri renkte kille sıvanmıştır. Atölyede ve firının çevresinde çok sayıda basit ve boyayla süslenmiş kil kapların kalıntıları ile içi boyalı kil kaplar bulunmuştur. Atölyede fazla sayıda kil kapların bulunması göz önüne alındığında firınlarda aynı anda çok sayıda kil kabın pişirildiği tahmin edilmektedir. 2010 yılında olduğu gibi 2011, 2013, 2014 yıllarında yapılan kazı çalışmalarında da Kültepe II yerleşim yerinde Orta Tunç Çă̆ı'na ait çömlek atölyeleri ve fırınlarına ait yeni yapı kalıntıları 
bulunmuştur. ${ }^{18}$ Tespit edilen tüm çömlek firınları biçim ve özelliklerine göre "Akdeniz tipli firınlar” grubuna dahil edilebilir. Kaynaklara baktı̆̆ımızda Akdeniz tipli firınların Hindistan, Mısır, Yunanistan, İspanya, Anadolu gibi dünyanın farklı bölgelerinde yaygın olarak kullanıldığını görmek mümkündür. ${ }^{19}$ Nahçıvan'ın yanı sıra Azerbaycan'da da bu tip çömlekçi firınları Mingeçevir' $\mathrm{de}^{20}$ ve diğer yerleşim yerlerinde bulunmuştur. Fırınların hepsinin üst kısmı kubbe biçiminde yapılmış ve pişirme odaları yanma odasının üzerinde inşa edilmiştir. Pişirme odası ile yanma odası arasındaki bölüme ve kubbenin üstüne küçük delikler açılmıştır. Fırının üst bölümündeki kısım baca olarak kullanılmıştır. Yanma odası ile pişirme odası arasındaki bacalar sıcaklığın eşit dağılarak kabın eşit sıcaklıkta pişmesi için kullanılmıştır. Fırının kapısı, 1sı kaybını önlemek amacıyla kapatılmıştır. Pişirme işlemi sırasında, herhangi bir çömlek ürünü yapıldığı hammaddenin mineralojik ve kimyasal bileşimine bağlı olarak ateşin etkisiyle çoğunlukla gri ve pembe olmak üzere diğer renklere dönüş̧ebilmektedir.

\section{Sonuç}

Nahçıvan bölgesindeki Tunç Çağı yerleşim yerlerinde bulunan çömlek firınları ve atölyeleri konusunda yapılan araştırmalar sırasında bazı bulgular gözlemlenmiştir. Bu bulgulara göre çömlekçilik, Nahçıvan'ın tarihî sanat dallarından biridir. Nahçıvan bölgesindeki Tunç Çağı yerleşim yerlerinde bu sanat dalıyla bağlantılı çok sayıda arkeolojik veri bulunmaktadır. Nahçıvan bölgesinin Tunç Çağı yerleşim yerlerinde bulunan çömlekçi firınları genel olarak Erken ve Orta Tunç çağına aittir. Erken Tunç Çağı'na ait çömlek firınlarının kalıntıları Kültepe I yerleşim yerinin III. ve V.; Kültepe II yerleşiminin ise VII. ve XI. yapı katında bulunmaktadır. Orta Tunç Çağı'na ait Kültepe II. yerleşiminde çömlek firınları ve atölyeleri tespit edilmiştir. Bu arkeolojik veriler hakkında bilgiler ayrı ayrı kaynaklarda ve arkeolojik kazı raporlarında verilmiş olsa da kapsamlı ve genel bir biçimde incelenmemiştir.

Araştırmalar esnasında Azerbaycan'ın diğer bölgelerinde olduğu gibi Nahçıvan'da da Erken Tunç Çağı'ndan itibaren çömlekçiliğin gelişim sürecinin başladığı belirlenmiştir. Orta Tunç Çă̆ı'nda çömlekçiliğin bağımsız bir alana dönüşmesi, bu sanat dalının gelişmesini sağlamıştır. Çömlekçiliğin gelişimi sonucunda Orta ve Son Tunç Çağı'ndan itibaren çömlek mamüllerinin çeşitliliğinin yanı sıra kalitesi de artmıştır.

18 Veli Aliyev ve Aide Memmedova, "II Kültepe Yaşayış Yerinde Yini Tedkikatlar,” Azerbaycanda Arkeoloji Tedkikatlar-2011 (Bakü: Xezer Üniversitesi Yayınları, 2012), 115-125; Veli Aliyev ve Aide Memmedova, “II Kültepe Yaşayış Yerinde Yini Tapıntılar (2013-2014-cü yıllar),” Azerbaycanda Arkeoloji Tedkikatlar-2013-2014, Bakü: Xezer Üniversitesi Yayınları, 2015, 161-168.

19 Daniel Rhodes, Kilns: Design, Construction and Operation (Philadelphia: Chilton Book Company, 1981), 38, 42; Sevim Çizer, "Seramikte Odun Pişirim Geleneği; Uzakdoğunun Yüksek Derece Fırınları", 98, Erişim 20 Kasim 2021,

https://mbeotblog.files.wordpress.com/2016/12/seramikte_odunlu_pisirim_gelenegi_uzakdo.pdf,

20 Kardaşhan Aslanov ve Raqim Vaidov, Drevniy Minqeçaur (Bakü: AN. Az. SSR Neşriyyatı, 1959), $144,145$. 
Kültepe II yerleşim yerindeki çömlek atölyesi birkaç bölümden ibaret olup geniş bir alanı kaplamaktadır. Bu atölyelerin çalışma alanı geniş tutulmuş ve kil ürünler birden fazla firınlarda pişirilmiştir. Çömlek firınlarının ve atölyelerin çevresinde çok sayıda basit ve boya ile süslenmiş çanak-çömlek kalıntılarının bulunması, bu yerleşim yerlerinde çanak-çömlek ve kil kapların kişisel ihtiyaçların karşılanmasının yanı sıra ticari amaçla da kullanıldığını göstermektedir. Nahçıvan çömlekçileri tarafından çeşitli teknik ve yöntemler ile beraber el aletleri de kullanılmıştır. Atölyede ve firınların çevresinde yanarak kömürleşmiş hayvan kemiklerinin yanında bulunmuş üzeri ve kenarında yağ izi olan kil kaplar, bu firınlarda odunun yanı sıra hayvan kemiklerinin de yakma amacıyla kullanıldığını göstermektedir. Fırının çevresindeki taş ve kemik aletler ise kapların ve diğer seramik mamüllerinin yapımında ve süslemesinde kullanılmıştır. Çömlekçiler basit kapların yanı sıra boyalı kaplar da yapmışlardır.

Sonuç olarak arkeolojik bulgular Nahçıvan bölgesinin Azerbaycan'ın önemli çömlekçilik merkezlerinden biri olduğunu göstermektedir. Nitekim biçim ve özelliklerine göre seramik eserlerin hepsi aynı değildir. Bunların birbirinden farklı olmasının nedeni hepsinin aynı atölyenin ürünü olmaması ve farklı çömlekçiler tarafından yapılmasıdır. Orta Tunç Çağı'ndan itibaren boya ile süslenmiş kapların yaygın olması, Nahçıvan `ın "Boyalı Kaplar Kültürü”nün önemli merkezlerinden biri olduğunu da kanıtlamaktadır. Kültepe I ve Kültepe II yerleşimlerinde ortaya çıkarılmış bulgulardan yola çıkılarak çömlek firınları, biçim ve özellikleri açısından "Akdeniz tipli firınlar" grubuna dahil edilebilir.

Hakem Değerlendirmesi: Dış bağımsız.

Çıkar Çatışması: Yazar çıkar çatışması bildirmemiştir.

Finansal Destek: Yazar bu çalışma için finansal destek almadığını beyan etmiştir.

Peer-review: Externally peer-reviewed.

Conflict of Interest: The author has no conflict of interest to declare.

Grant Support: The author declared that this study has received no financial support.

\section{Kaynakça/References}

Abibullayev, Osman. Enolit i Bronza na Territorii Nahiçevanskoy ASSR. Bakü: İlm Yayınları, 1982. Aliyev, Veli. Azerbaycan'da Tunç Devrinin Boyalı Kablar Medeniyyeti. Bakü: İlm Yayınları, 1977. Aliyev, Veli. Kadim Nahçıvan. Bakü: İlm Yayınları, 1979.

Aliyev, Veli ve Aide Memmedova. "II Kültepe yaşayış yerinde 2009-cu yıl tedkikatları." Azerbaycanda Arkeoloji Tedkikatlar-2009. Bakü: Xezer Üniversitesi Yayınları, 2010, 126-130.

Aliyev, Veli ve Aide Memmedova. "II Kültepe yaşayış yerinde yini tedkikatlar (2010)." Azerbaycanda Arkeoloji Tedkikatlar-2010. Bakü: Xezer Üniversitesi Yayınları, 2011, 126-135.

Aliyev, Veli ve Aide Memmedova. "II Kültepe yaşayış yerinde yini tedkikatlar". Azerbaycanda Arkeoloji Tedkikatlar-2011. Bakü: Xezer Üniversitesi Yayınları, 2012, 115-125. 
Aliyev, Veli ve Aide Memmedova. "II Kültepe yaşayış yerinde yini tapıntılar (2013-2014-cü yıllar)". Azerbaycanda Arkeoloji Tedkikatlar-2013-2014. Bakü: Xezer Üniversitesi Yayınları, 2015, 161168.

Aliyev, Veli. Kultura Epoxi Sredney Bronzı Azerbaydjana. Bakü: İlm Yayınları, 1991.

Alesker Alekperov, İssledovanie po Arxkeoloqi Azerbaydjana. Bakü: Az. SSR Yayınları, 1960

Aslanov, Kardaşhan ve Raqim Vaidov. Drevniy Minqeçaur. Bakü: AN. Az. SSR Yayınları, 1959.

Alekperov, Alesker. Íssledovanie po Arxkeoloqi Azerbaydjana. Bakü: Az. SSR Yayınları, 1960.

Çizer, Sevim. "Seramikte Odunlu Pişirim Geleneği: Uzak Doğu'nun Yüksek Derece Fırınları”. Erişim 20 Kasım 2021, https://mbeotblog.files.wordpress.com/2016/12/seramikte_odunlu_ pisirim_gelenegi_uzakdo.pdf

Rhodes, Daniel. Kilns: Design, Construction and Operation. Philadelphia: Chilton Book Company, 1981.

Seidov, Abbas. Pamyatniki Kura-arakskoy Kulturı Nakçıvane. Bakü: Bilig Yayınları, 1993.

Seidov, Abbas. Rannebronzovaya Kultura Nakçıvana. Voronej: İlm Yayınları, 2002. 
